\title{
Factors Responsible for Oral Polio Vaccine Rejection by Some Parents in Northern Nigeria
}

\author{
Article by Adamu, Umar Husaini \\ Public Health Practitioner, World Health Organization, Nigeria \\ E-mail: drumarhusaini@gmail.com
}

\section{Background}

Nigeria is the most populous country in Africa, with a population of over 140 million and it is one of the fastest growing nations in the world. It has a very rich cultural heritage, with over 300 ethnic and linguistic groups. The major ethnic groups are Hausas, Yorubas and the Igbos. The most popular religions are Islam (mainly in the Northern Parts), Christianity (mainly in the southern parts), and traditional African religion, mainly freely practiced alongside other religions (Babalola and Aina, 2004).

The population of the Northern Nigeria is more than that of the southern part of the country. The first census of Nigeria was conducted in 1911 about three years before creation (Yakasai, 2006). This means that there are more children in the northern Nigeria than other part of the country. The issue of polygamy which is largely practice in the northern part of Nigeria also contributed to the large number of children in the area.

Childhood immunization is designed to improve child health and reduce morbidity and mortality. Nigeria commenced immunization activities many years ago, focusing initially on the control of yellow fever and smallpox. It launched the Expanded Programme on Immunization (EPI) in 1979 due to global increased in mortality of children under the age of 2 years as a result of vaccine preventable diseases. The programme was successful at the beginning but declines in uptake of the services were quickly observed. Joint efforts of the Federal Government, State agencies and international organizations (UNICEF, WHO) led to Nigeria attaining Universal Childhood Immunization (UCI) in 1991 (Federal Ministry of Health, 1992; in Babalola and Aina, 2004).

Since the mid -1990s, Nigeria has continued to witness fluctuations in immunization coverage for all vaccine- preventable disease which resulted to bad consequences on children's health and survival. Data from the 2003 National Immunization Coverage Survey revealed that only 12.7 percent of the children aged 12- 23 months were fully immunized. At that time, Nigeria emerged the country with the highest number of Wild Polioviruses (WPV) in the world (WHO, 2005).

Increased widespread transmission of WPV was reported in highly endemic State of northern Nigeria (Kano, Katsina, Jigawa, Kaduna and Bauchi) (Babalola and Aina, 2004).

The Global Polio Eradication Initiative set targets to wipe out polio in 125 countries by 2005 . Unfortunately, Nigeria remains one of the few reservoirs of the wild poliovirus around the world (Babalola and Adewuyi, 2005).Despite the progress achieved since 1988; children in all countries are at risk of contracting the disease as long as a single child remains infected with poliovirus. The poliovirus can easily be imported and spread rapidly amongst unimmunized population in polio-free countries (WHO 2007a).

According to P.H.A.C. (2006) in 2004 sub-Saharan Africa experienced epidemic levels of polio transmission resulting from the suspension of immunization activities in a number of Nigerian states. The transmission of poliovirus increased within these states.

Eventually, poliovirus from Nigeria spread to the neighbouring countries with low routine immunization coverage resulting in the re-infection of 12 previously polio-free countries in Africa. 
DOI: $10.21522 /$ TIJPH.2013.05.04.Art046

ISSN: $2520-3134$

Nigeria remains the only polio-endemic country in the African region and transmission continues to remain high (P.H.A.C, 2006). This is because the political leaders of Kano, Zamfara, Bauchi, and Niger State in the northern Nigeria brought the immunization campaign to a halt by calling on parents not to allow their children to be vaccinated against poliomyelitis (Islamic Leaders' Fears of US 'Plot' Put Millions at Risk for Polio - CNSNews.com 28/10/2003; in Yahya, 2005). They suspect that the polio vaccines being offered free of charge are contaminated with an anti-fertility agent that would sterilize their children or perhaps infect them with the AIDS virus. However, WHO's target of wiping out Polio by 2005 failed after the Muslims Northern Nigeria halted the Polio immunization drive for eleven months in 2004 and 2005.

People in the northern Nigeria generally did not see polio as a priority disease amongst the many others affecting their children. Unfortunately, only few research projects were conducted to find out factors responsible for oral polio vaccine rejection by some parents in the northern Nigeria. Consequently, the need to investigate factors responsible for oral polio vaccine rejection by some parents in northern Nigeria has become even more compelling as there are other reasons that are unknown. Finding these reasons would help in overcoming the problem.

\section{Research aim}

The purpose of this study is to explore factors responsible for oral polio vaccine rejection by some parents in northern Nigeria.

\section{Specific objectives}

1. To identify the reasons for the oral polio vaccine rejection in northern Nigeria.

2. To assess knowledge about childhood immunization.

3. To make some suggestions on how to improve the uptake of polio vaccine.

\section{Literature review}

Immunization refusal has existed long ago in different parts of the world including Africa before the resent one which took place in northern Nigeria.

The polio vaccine rejection also happened in India in 2004, where the conspiracy theories rampant among Muslins in the eastern Bihar State. In that case again, the purpose of immunization was thought to be to cut down on population; in the slums of Gaya, about 60 miles from the state capital, Patna, where many people regarded the antipolio drops as a deceptive strategy to control the birth rate (Weblog, 2004).

Reasons for vaccine rejection can explore by looking at the work of Muktar (2003) which was conducted with the aim to explore factors responsible for rejection of polio immunization campaign as a case study of Tarauni LGA Kano State. reasons for rejection include: (1) Contains HIV/AIDS Virus (2) Will affect child's fertility later in life (3) Too many repetitions (4) Cannot protect the child (5) Child was sick during the NIDs (6) Fear of paralysis (7) Service producer not friendly (8) Fear of fever (9) Can kill the child

People were more concerned with HIV/AIDS among the reason for rejection (for having the highest percentage) than any other reason. Fear of fever and can kill the child had smaller percentage as for the reasons for the OPV rejection.

Yahya (2006) conducted a study to explore the political and cultural angles of the Polio controversy revealing deeper dimensions and complex factors that have contributed to rejection of the Oral Polio Vaccine (OPV) in northern Nigeria. Reasons given by the participants for the refusal of the vaccine were based on the grounds that the vaccine contained contraceptives constituent which was added to the vaccine in order to reduce the number of children being delivered by Muslims in the northern Nigeria. The Kano State technical committee on polio immunization claimed of anti-fertility agents detected in samples of the vaccine which were not declared on the labels of the bottles and vials. Some described them as ill-founded rumours 
grounded in misinformation spread by a few with misguided intent, to be corrected through education.

Simpson, Lenton and Randall (1995) conducted study on parental refusal to have children immunized. A total of 106 children were found to have had no immunizations during the six years. (The commonest for refusal were homoeopathy ( 22 children) and religious beliefs of the parents (17 children). The Christians think that healing is the natural result of drawing closer to God and therefore those immunizations were not necessary. Five children had medical reasons while other (17) had various individual reasons. Seven children had just started immunization while parents of the remaining 19 children gave no reason for non-immunization.

Pareek and Pattison (2000) conducted a study to identify reasons for the low uptake of MMR vaccination in Birmingham. The study revealed that major reason for the low uptake of the MMR vaccination was that it was not perceived to be important for children's health; particularly the second dose. Side effects like malaise and autism contributed to low uptake.

Kennedy, Brown and Gust (2005) conducted a study to describe the socio-demographic factors, vaccine beliefs, and behaviours associated with parents' opposition to compulsory vaccination, and to assess the association between residence in a state allowing philosophical exemption and parental opposition to compulsory immunization. The study found that beliefs associated with being opposed to compulsory vaccination include: agreement that the body's defences are strong enough to protect against vaccine-preventable disease without immunization; disagreement that vaccines are necessary to prevent certain diseases; and a belief that vaccines are only somewhat, or not, important to a child's health.

Dannetun at el. (2005) conducted on parents' attitudes regarding their choice to postpone or abstain from vaccinating their child in the Country of Östergötland in Sweden. Result of the study revealed that 26 of the 203 children had received MMR vaccination but this had not been registered and of those not vaccinated, 40 percent of the parents had decided to abstain and 60 percent to postpone vaccination. The most common reason for non-vaccination in both groups was fear of the side effects and beliefs concerning maturity and natural immunity.

The gap in the literature review is that even those that conducted their studies based on polio, they did not recruit only parents that refused their children to be vaccinated against polio. They recruited parents randomly irrespective whether they refused their children to be vaccinated against polio or not. Others conducted their research in only one local government area of Kano State.

Following this review of the literature and the identification of the gap in the studies, this study will explore factors responsible for oral polio vaccine rejection by some parents in northern Nigeria using only participants that refused their children to be vaccinated against polio and data collection tool is in-depth semi-structural interview.

\section{Research methodology}

Qualitative methodology was chosen because it is an appropriate design to answer the research question. This is because it enhances description and method is flexible. It aims to study people in their natural social settings and to collect naturally occurring data (Bowling, A., 2002).

\section{Study site}

Our study was conducted in Kano State (one of the northern Nigeria states) having the highest cases of Polio cases in Nigeria and the world in general. It was conducted in the following LGAs: Dala, Fagge, Gwale, Kano Municipal, Kumbotso, Nassarawa and Tarauni.

\section{Research design}

The study used a qualitative design to describe factors responsible for Oral Polio Vaccine $(\mathrm{OPV})$ rejection by some parents in the northern Nigeria. Data sources were mainly in-depth 
DOI: $10.21522 /$ TIJPH.2013.05.04.Art046

ISSN: $2520-3134$

open-ended semi structural interviews. Interviews data were recorded using tape recorder which was transcribed verbatim.

\section{Sample/ Sampling strategy}

Ten participants (nine males and one female) were selected using purposive sampling method using the following inclusion criteria:

1) General public of Kano State.

2) Participants that were born and grew up in Kano State.

3) Those who chosen not to have their children vaccinated against polio.

\section{Data collection}

The study used tape recorder in data collection. Before the commencement of the interviews, participants signed consent forms and a quiet area (in their houses) was used for the interview so that participants could reflect on their experiences and audio taping could be conducted. Only one or two interviews were conducted in a place which was not very quiet (working places of the participants), where they chose to be interviewed. Interviews were then transcribed verbatim.

\section{Ethical issues}

Ethical approval was granted by Kano State Ministry of Health and Ethical Committee of the University of Wolverhampton. All participants gave informed written consent to be interviewed.

\section{Data analysis}

The in-depth interviews were recorded and transcribed verbatim by the researcher. Data analysis was done manually using themes i.e. using the Colaizzi's (1978) suggested stapes for data analysis.

\section{Research findings}

Common themes present in factors responsible for oral polio rejection in the northern Nigeria were organized into theme clusters (see Table 1 below). The theme clusters derived from the data sources included the following

- Polio is a means of contraception.

- Polio vaccine causes diseases.

- Too much emphasis on polio.

- Polio vaccine does not prevent polio.

- Children do survive without immunization.

- Polio vaccine was condemned.

Table 1. Clusters of themes: factors responsible for OPV rejection

\begin{tabular}{l} 
Polio vaccine is a means of contraception \\
- Polio vaccine is for family planning. \\
- Polio vaccine causes infertility. \\
\hline Polio vaccine causes diseases \\
- Polio versus HIV infection. \\
- Polio vaccine is contaminated. \\
- Woo much emphasis on polio \\
- Malaria is more dangerous than polio. \\
- Better to alleviate poverty than polio. \\
- Too many rounds of polio immunization exercises. \\
\hline
\end{tabular}




\begin{tabular}{|l|}
\hline - There is hidden agenda in polio. \\
\hline Polio vaccine does not prevent polio \\
\hline Children do survive without immunization. \\
\hline Polio vaccine was condemned \\
\hline
\end{tabular}

\section{Polio vaccine is a means of contraception}

Polio vaccine is a means of contraception incorporated polio vaccine is for family planning, and polio vaccine causes infertility.

\section{Polio vaccine is for family planning}

Polio vaccine is for family planning was described, "so that time we asked people, they said that polio they put something like family planning inside".

\section{Polio vaccine causes infertility}

The perception that polio vaccine causes infertility is in the mind of other people as one of the participant said: "some of them said among the ingredients which were used to prepare the immunization there is something, there is something which I don't know its name, but the consequences of using it is it causes infertility peculiarly to female children. So that is why the people began to, to doubt the sincerity of the vaccination".

\section{Polio vaccine causes diseases}

Polio vaccine causes diseases incorporated polio vaccine versus HIV infection, and polio vaccine is contaminated.

\section{Polio vaccine versus HIV infection}

More than half of the participants said that they were told that the polio vaccine contains HIV/AIDS. This is one of the greatest fears in the participants' mind:

"They said this vaccine was contaminated by either HIV infection or with family planning something in the vaccine".

Another participant argued that:

"Even in Lagos there is one doctor, I can't remember his name, so he said immunizations.... The introduction immunization is not perfectly to help the teaming population of the third world nation but also to reduce them".

\section{Polio vaccine is contaminated}

Many people were concerned about the content of the polio vaccine. Polio vaccine is contaminated was described:

"I worked once with one consultant paediatrician, who was a consultant for over 10 years as a consultant and giving lectures at the teaching hospital and he is telling me that this is not good, is contaminated. So who am I not to believe him?"

To one of the participants, bacteria were added to the vaccine which causes Hypertension and Pneumonia:

'so that ' bactis wey' they carry putting inside polio,... when they grow that 'bactis' they give us like AIDS, they give us like that Hypertension, they give us like that what you call it Pneumonia".

\section{Too much emphasis on polio}

Too much emphasis on polio incorporated why polio and no other diseases?, malaria is more dangerous than polio, better to alleviate poverty than polio, too many rounds of polio immunization exercises, polio is not our priority problem and there is hidden agenda in polio. 
DOI: $10.21522 /$ TIJPH.2013.05.04.Art046

ISSN: $2520-3134$

\section{Why polio and no other diseases?}

Participants keep asking themselves why government give more emphasis on polio and no other diseases. This is the question that they don't know the answer yet:

"When you go to the hospital may be you are suffering from headache, no one will give you a single Panadol free of charge but the immunization causes a lot of money so and it is still given to poor people free of charge".

\section{Malaria is more dangerous than polio}

To Nigerians in general, malaria is more dangerous than polio because it kills thousands of people everyday including pregnant women and children:

"Our problem is Malaria, typhoid and these diseases that are quite frequent...... when you go round hardly you find may be 2 percent of the population suffering from polio but about 20 percent are suffering from Malaria and typhoid".

\section{Better to alleviate poverty than polio}

Participants expressed a variety of reactions to the relationships with poverty alleviation: "See, most of our people here are in poverty they lack work, they lack food".

Participants prefer to see government introducing programmes that would help in alleviating poverty than eradicating polio. To them poverty (hunger) is more dangerous than polio:

"Why don't they bring us food for those who are in hunger"?

\section{Too many rounds of polio immunization exercises}

Participants were not happy by the way the government is repeating the polio exercise over and over again this time around:

"I will see no reason, see no reason why this polio exercise will be repeating month after month or time, from time to time".

\section{Polio is not our priority problem}

Participants put much emphasis on malaria and typhoid as the diseases that are disturbing them more frequent than polio:

"There are much more important concerns to address example malaria, typhoid and others. Why don't the foreign countries help us eradicate

Malaria instead?"

\section{There is hidden agenda in polio}

Due to concern shown by the Western world on polio, many people think that there is a hidden agenda in polio immunization:

"People are doubting about there must be a hidden agenda inside that polio".

\section{Polio vaccine does not prevent polio}

Some of the participant argued that they don't believe that the polio vaccine does prevent polio because even the immunized children can be affected by polio:

"Another thing that happened to further put him off these vaccines, is our neighbour's daughter who was vaccinated but instead came down with the polio disease and is now in fact paralyzed".

\section{Children do survive without immunization}

Some of the participants believe that children can survive without immunization: "without immunization people or children can survive" 
For this reason some parents have never in their life vaccinated their children:

"I have three kids, but none of them have ever been immunized since birth"

A participant said:

"But the only one that I don't believe in, that was polio".

Another participant said that his daughter hasn't received any immunization:

"My daughter, she didn't receive anything up till now. She has any Immunization? No!"

\section{Polio vaccine was condemned}

Doctors were the first people in Nigeria to start condemning the polio vaccine:

"You see, when these speculations start arising that the vaccine is contaminated, fortunately it is the elites who started this, the doctors, consultants".

\section{Discussion}

From the study, various factors responsible for oral polio vaccine rejection were identified. Many factors (themes) in the study were identified previously in other research in the literature review while other finding (for example, Polio vaccine was condemned) was unique to this study.

Among the findings, parents showed more concern on the finding "polio vaccine is a means of contraception' which means that OPV contained contraceptive ingredient which will make their children sterile later in life. This finding was also identified in Mukhtar (2003), Yahya (2006), UNICEF (2001), Milliomouno et al. (2006) and NPI (2006) in the literature review. Participants see OPV as a means of family planning which is not allowed in Islam and majority of the inhabitant of northern Nigeria are Muslims. Religion affects all aspects of life in Nigeria and religious leaders play an important role in shaping community norms and in their day to day activity. The 2003 polio controversy of the northern Nigeria was connected with religion in one way or the other.

"The early cries against the vaccines by a number of religious leaders in northern Nigeria found a platform when taken up in July 2003 by the Chairman of the Supreme Council for Sharia in Nigeria (SCSN), Dr. Datti Ahmed. He alleged that there was a strong likelihood that the vaccine had been contaminated with anti-fertility agents and that it should therefore not be administrated to children until full investigations had been conducted (Daily Trust Newspaper, Nigeria 30 December, 2003; in Yahya 2006, p.9)".

Parents relate the OPV Controversy with their past experience in the Pfizer scandal. Some years back, Pfizer used people in Kano for testing Meningitis drugs without fully informing them of the risks attached to it (Wise, 2001). This was cited by many as a reason for the mass rejection of polio vaccination in northern Nigeria in recent years ('Pfizer wins early Nigeria battle', BBC News - 26 June, 2007). Due to this reason, many people think that there is a hidden agenda in polio immunization. They think that the aim of polio immunization is to reduce the number of the growing third world countries:

"Even in Lagos there is one Dr, I can't remember his name, so he said immunizations.... The introduction of immunization is not perfectly to help the teaming population of the third world. Nation but also to reduce them" (Interview number 9). Another reason given for the OPV rejection in this study was that the vaccine causes diseases. One of the findings under this theme that the vaccine causes HIV was also identified in Mukhtar (2003), UNICEF (2001), and NPI (2006). In Nuwaha et al. (2000) the low attendance of the National Immunization Day was linked with the rumour that the NIDs are a ways for testing HIV/AIDS. In Milliomouno et al. (2006) rumours also reflected concerns that vaccination needles were transmitting HIV/AIDS. These show that the relationship between NIDs and routine immunization was generally poorly understood. But however, the fact that vaccination needles were transmitting HIV/AIDS could be possible especially if needles were re-used. Fear of HIV/AIDS really affected immunization coverage in many part of the world. The rejection due to fear of HIV will put the life of many 
DOI: $10.21522 /$ TIJPH.2013.05.04.Art046

ISSN: $2520-3134$

children in danger because as far as some children left un-immunized against polio, other children can be affected by the disease and it will be therefore difficult to eradicate the disease as done to Small pox.

According to one of the participants, OPV contaminated with bacteria which can cause Hypertension and Pneumonia. This was his reason for refusing the polio vaccine. It is not surprising because government did not listen to people about their needs and therefore they can do anything they could to sabotage the immunization exercise for government to listen to them. One of the participants even said that the vaccines brought to them are expired ones:

"We heard that this type of immunization has its own culture that when it cannot take so long time may be in light but we see when these vaccines are brought into our country, we see how they are display in the airport for so long time, may be is the expired one that is brought to us, so and it is when is given to our children instead of preventing them from the said diseases they may even cause them something" (interview number 6).

Each vial of vaccine has a vaccine vial monitor (VVM) on the bottle which can show whether the vaccine is expired or not and all the vaccinators were trained on how to read the vaccine vial monitor during training before each round of immunization exercise. One cannot say a vaccine is expired or not unless he/she was trained on how to read the vaccine vial monitor, even among the doctors not every doctor can say the vaccine is expired unless he/she know how to interpret the vaccine vial monitor. The World Health organization recommended the use of vaccines that are in stage one and two only (good vaccine) and reject stage three and four (expired vaccine) and all the vaccinators are aware of this. So one has to know this before saying a vaccine is expired.

Too much emphasis on polio vaccine was also identified in Mukhtar and UNICEF (2001) in the literature review. People do not see polio as a priority disease to them. They also don't understand why they were being followed to their own houses to be given this expensive vaccine free of charge while they can't be provided with cheap essential drugs free of charge in the hospitals. To them this power is too much for only polio.

Previously, it used to be only fixed post teams for immunization but now there are house-tohouse teams. In Africa, malaria is the number one killer disease and not polio. It kills thousands of men, women and children every day and government seems to do nothing about it. According to Pasvol (2005) almost two billion people in endemic areas are at risk of malaria, and each year it is estimated that up to 250 million clinical cases occur and over one million die, largely among African children.

Most of the hospitals in Nigeria were filled with malaria or malaria related cases. This is not all, other people see Measles, typhoid fever, and yellow fever more important than polio if you keep malaria aside.

Cuba is not as rich as Nigeria, but they manage to eradicate malaria many years ago. This emphasis given to polio was noticed not only in Nigeria but in other African countries such as Uganda and Kenya as in UNICEF (2001) as in the literature review. Parents in Uganda and Nigeria keep on asking questions which they are willing to know the answers as in UNICEF (2001, P.18) in the literature review:

"Why spend all those resources on polio when it kills few or no people? Malaria is the number one killer of children. Most people cannot afford treatment, so why devote limited resources to polio?, If global organizations and governments want to help, why not have them put resources into disease that kill?, If polio is actually caused from faeces, if I improve sanitation/hygiene, how could I come into contact with polio?, If OPV is safe and we know its ingredients, why don't we manufacture OPV in our country?"

People said that they are tired of the exercise because of too many repetitions of the exercises. Previously, polio immunization exercises were conducted about 3-4 times a year, but nowadays almost every month. Due to the frequency of the polio exercise, when you talk about 
immunization many peoples' mind go back to polio. This is something people must question and if people were not enlightened about the importance of these frequent polio exercises and about polio in general, polio vaccine would be continue to be rejected not only in Nigeria but in other countries.

Negative rumours about polio immunization led to many parents making decision to avoid OPV. Some parents expressed the belief that immunization is a good way of preventing childhood diseases and they accept all types of immunization with the exception of polio.

Puberty alleviation is another thing that parents emphasized. Although some parents acknowledged the importance of immunization but they argued that children have to be fed and clothed before considering immunization. This was also identified in UNICEF (2001) of the literature review. They added that if government and NGOs want them to accept polio vaccine, they should provide food for them. There were so many complain of people not been provided with essential social amenities. No drinking water, no light, no jobs, no good roads, no drugs in the hospitals and the standard of education is falling everyday but government is emphasizing on OPV and spending billions of naira on the programme.

In Kano State alone, most of the industries were closed down due to power failure and as a result only God knows how many people became unemployed. Many Nigerians are living below the poverty line and government is not doing anything about it while Nigeria is one of the richest countries in Africa. Participants prefer to see government introducing programmes that would help in alleviating poverty than eradicating polio. To them poverty is more dangerous than polio.

Because of the above reasons, that was why people were saying that there is hidden agenda in polio and decided not to immunize their children against polio.

Some parents have the belief that the polio vaccine does not prevent polio. This theme was also identified in Mukhtar (2003) as cannot protect the child. For some parents polio is a hereditary disease which runs in a family like Asthma and Hypertension. According to them, as far as you have a family history, one of your children or great grandchildren most has it. For them there is no any medication be it traditional or western treatment that can cure or prevent it and therefore they don't care to look for prevention for it. Other parents believed that even immunized children can be affected by polio and therefore they don't bother to immunize their children against polio. One father of two said that he will never immunize any of his children again because he has a baby which had the polio immunization but now she is paralyzed as a result of polio.

For these types of parent immunization is not perceived to be important for children's health. A similar situation was also identified in Pareek and Pattison (2000) in the literature review where the major reason for low uptake of MMR vaccination was also not perceived to be important for children's health. But the only problem here is that one could not be sure if these children affected by polio after been immunized, had complete dose of polio vaccine or not.

Most of the parents do not know how many times the child is supposed to be immunized against a particular disease in order to reach the booster dose level. Some think that immunizing child once is enough for the life time. Another problem is that a lot of people think that it is only polio vaccine that is given during house-to-house immunization not knowing that other antigens can be also given during this process. Father cannot tell exactly which type of immunization his child had and which one he didn't. This is because in an African setting most of the times fathers are out to look for food while only mothers are at home to take care of the house. Even if the house-to-house teams would come, they would probably meet only the mother and not the father. Therefore mother is the only person that can tell exactly which type of vaccine her child received. One of our participants a mother of three said:

"I have 3 kids, but none of them have ever been immunized before since birth because their father is against it. My first child is 5years old, second is 15 months old the third is 3 months old. 
DOI: $10.21522 /$ TIJPH.2013.05.04.Art046

ISSN: $2520-3134$

I only had them Immunized for BCG for the first time last week without their father's knowledge of course, because I believe it must have its uses" (interview number 10).

Other parent said that polio vaccine does not prevent polio because the disease is caused by Jinn. This was also identified in the work of Yahya (2006) of the literature review. In Hausa community, Poliomyelitis is called 'Shan-Inna'. 'Inna' literarily means mother, but in this case it means a powerful female spirit (Jinn). So the term 'Shan-Inna' in Hausa communities refers to polio that is a disease in which the powerful female spirit (jinn) consumes the legs of human beings.

According to some parents, the disease affect a person who normally sits at the door entrance, or who enters toilet without prayer, or who enters a refuse dump when the sun is overhead or in the night. The mother of the jinn may wipe him out and this causes the disease. People affected by this disease (polio) are normally taken to traditional healer and sometimes to religious leaders who do 'Ruqiyya' (prayer) for them and sometimes give them amulets to wear. If this failed, they then take the child to hospital for help. Some parent do the reverse, that is take the child first to hospital if nothing can be done then the go to the traditional healers. It is therefore difficult to convince some people that the two drops of polio vaccine into the mouth can prevent polio.

Some parents do not see polio as a life threatening disease. For them polio can only paralyzed one but does not kill. People affected by polio are seen crawling in town on their hands and knees, while those that have money among them moving on tricycles (motorcycles) going about their business without any problem. Some years back, people affected by polio in the northern Nigeria used to go to Arab Countries like Saudi-Arabia beg and come back to Nigeria with a lot of money. They built mansions, bought automatic cars, and engaged in bureau de change business. Due to high level of poverty in Nigeria people saw them as fortune individuals that time. Nowadays, people affected by polio are normally seen around traffic lights and roundabouts selling mobile phones recharge cards and not in the hospitals as those suffering from other diseases. This alone indicates that polio is not regarded as a serious disease in northern Nigeria.

Children do survive without immunization was also identified in Kennedy, Brown and Gust (2005) and NPI (2003) in the literature review. No disease occurred in non-immunized older children in the family is a similar reason for non-immunization identified in Mathew, Babbar and Yadav (2002) in the literature review. Some parents do believe that their children can survive without immunization based on their experience in the hard to reach areas and those parents that have never immunized their children in their life. In Africa, there are some areas which vaccinator normally find them difficult to reach and these are areas that you can find under-five children which were never immunized in their life. Based on this fact, some parent decided that it is better not to immunize a child than to immunize him with a contaminated vaccine.

The theme, polio vaccine was condemned, was not identified in previous studies. The 2003 polio controversy in Nigeria started when Dr. Datti Ahmad who is a medical doctor said that there was a strong likelihood polio vaccine was contaminated with anti-fertility agent. Dr. Datti Ahmed is a medical doctor, and people have respect and confidence on medical doctors especially when it comes to medical issues. Other doctors joined Dr. Datti Ahmed and condemned the polio vaccine. At that time the Kano State Government declared the suspension of the polio vaccine exercise and sent a delegation to Indonesia to investigate the content of the polio vaccine. After investigation, it was found the vaccine to have contained some anti-fertility ingredient which was not labelled on the vial of the vaccine (Hasslberger 2004). From that time, Kano State Government condemned the vaccine too and planned to buy the vaccine from Muslims countries. 


\section{Conclusion}

In this study, qualitative methodology was used to explore factors responsible for oral polio vaccine rejection by some parents in northern Nigeria. From the study it can be concluded that some parents in the northern Nigeria (Kano State) are still refusing their children to be vaccinated against polio.

\section{Limitation of the study}

The limitation of this study is that the sample size was small due to the fact that it was a small and independent research. There is need for another research to be conducted in which only women (parents) who refused their children to be vaccinated against polio would participate. This is because mother is the only person that can tell exactly which type of vaccine her child received especially in African setting where fathers are always out to look for food while mothers are at home with the children.

\section{Recommendations}

1. There is need for Government to listen carefully and respectfully to the parent's concerns on other diseases that are disturbing them as well as the issue of free essential drugs in the hospital which will give people courage to accept the polio vaccine.

2. There is need for health workers to educate parents on the importance polio immunization and other immunization for them to realize that OPV is safe and does not contain any contraceptive ingredient or HIV/AIDS virus. This may correct any misperception and misinformation about the vaccine.

3. There is need for the government to explain clearly to the people the importance of frequent rounds of polio immunization exercises through media as many people do not understand its importance.

4. There is need for the government to implement poverty alleviation programmes. This will convince people that the government is doing something towards poverty alleviation and not on polio alone since many people pointed out that poverty alleviation is better than polio eradication. This will improve the immunization turn out.

5. Since many people pointed out that malaria is their number one problem and not polio, there is need for more anti-malarial, mosquito nets, and insecticides to be distributed to parents free of charge or at subsidized price during the National immunization Days. This will also improve the immunization turn out.

6. As some of the participants said that polio vaccine does not prevent polio, there is need for health workers to educate people that immunizing a child with the polio vaccine once or twice does not attain the booster level. For those children that received the booster dose, other conditions may produce the same clinical picture which can be mistaken as polio.

\section{References}

[1]. Babalola, S. and Adewuyi, A. (2005) factors influencing immunization uptake in Nigeria: theorybased research in six states. Abuja: Nigeria Partnership for Transforming Health Systems.

[2]. Babalola, S. and Aina, O. (2004) Community and systemic factors affecting the uptake of immunisation in Nigeria: a qualitative study in five state. Abuja: Federal Ministry of Health (National Report).

[3]. Beitz, J.M. and Goldberg, E. (2005) the lived experience of having a chronic wound: a phenomenologic study. Dermatology nursing, 17 (4), p.272-305.

[4]. Bowing, A. (2002) Research methods in health: investigating health and health services.2nd ed., Buckingham: Open University Press. 
DOI: $10.21522 /$ TIJPH.2013.05.04.Art046

ISSN: $2520-3134$

[5]. Calvente, M.G., Fernandez, L.A.L. and Cantalejo, E.S. (1993) Identification of factors associated with deficient immunization coverage. European Journal of Public Health, 3 (2), pp.97-103.

[6]. Clifford, C. (1997) Nursing and healthcare research: a skill based introduction. 2nd ed., London: Prentice Hall.

[7]. Dannetun, E., Tegnell, A., Hermansson, G., and Giesecke, J. (2005) Parents' reported reasons for avoiding MMR vaccination. Scandinavian Journal of Primary Health Care, 23, pp149-153.

[8]. Decrop, A. (2004) Trustworthiness in qualitative tourism research. In Phillimore, J. and Goodson, L. (eds.) Qualitative research in tourism: ontologies, epistemologies and methologies. London: Taylor \& Francis Group, pp.156-159.

[9]. Denzin, N.K. and Lincoln, Y.S. (eds.) (1994) Handbook of qualitative research. London: Sage Publication.

[10]. Detels, R., McEwen, J., Beaglehole, R., and Tanaka, H. (eds.) (2004) Oxford textbook of public health. 4th ed., Oxford: Oxford University Press.

[11]. Feilden Battersby Health Systems Analysts (2005). The state of routine immunization services in Nigeria and reasons for current problem. Abuja: Feilden Battersby Health System Analysists.

[12]. Fredrickson, D.D., Davis, T.C., Arnold, C.L., Kennen, E.M., Humiston S.G., Cross, J.T., and Bocchini, J.A. (2004) Childhood immunization refusal: provider and parent perceptions. Family Medicine, 36 (6), pp.431-439.

[13]. Green, J. and Thorogood, N. (2005) Qualitative methods for health research. London: Sage publication.

[14]. Gorski, P.C. (1998) Racial and gender identity development in white male multicultural educators and facilitators: toward individual processes of self-development [online].Virgina: University of Virgina [cited 25th July 2007].

[15]. http://home.earthlink.net/ gorski/dissertation/method.html.

[16]. Hasslberger, J. (2004) Nigeria: polio vaccine found contaminated [online].Rome: La Strega [cited 18th July 2007].

[17]. http://www.newmediaexplorer.org/sepp/2004/03/10/nigeria_polio_vaccine_found_contaminated.htm.

[18]. Holloway, I. and Wheeler, S. (2002) Qualitative research in nursing. 2nd ed., Oxford: Blackwell Publishing Company.

[19]. Kennedy, A.M., Brown, C.J. and Gust, D.A. (2005) Vaccine beliefs of parents who oppose compulsory vaccination. Public Health Rep., 120, pp. 252-258.

[20]. Leach, M. (2006) Vaccine anxieties: science, technology and public engagement. Brighton: Institute of Development Studies.

[21]. Marshall, C. and Rossman, G.B. (1989) Designing qualitative research. London: SAGE Publication.

[22]. Marshall, C. and Rossman, G.B. (1995) Designing qualitative research. 2nd ed., London: SAGE Publication.

[23]. Mathew, J.L., Babbar, H. and Yadav, S. (2002) Reasons for non-immunization of children in an urban, low income group in North India. Tropical Doctor, 32 (3), pp.135-138.

[24]. Maxwell, J.A. (1996) Qualitative research design: an interactive approach. London: SAGE Publication.

[25]. Miles, M.B. and Huberman, A.M. (1994) Qualitative data analysis. 2nd ed., London: SAGE Publication.

[26]. Millimouno, D., Diallo, A.A., Fairhead, J. and Leach, M. (2006). The social dynamics of infant immunization in Africa: the case of the Republic of Guinea. West African Social Science and Immunization Network (WASSIN) paper 2 Forthcoming IDS Working Paper.

[27]. Morse, M.J. (1989) Strategies for sampling. In Morse, M.J. (ed.) Qualitative nursing research. London: Sage Publications, pp.127-145.

[28]. Mukhtar, B.M. (2003) Factors responsible for rejection of oral polio immunization campaign a case study of Tarauni LGA, Kano State. Zaria: Ahmadu Bello University. 
[29]. [NPI] National Programme on Immunization (2006) Study report: knowledge, perception and beliefs about childhood immunization and attitude towards uptake of poliomyelitis immunization in northern Nigeria. Abuja: National Programme on Immunization.

[30]. Northern Arizona University (1997) Lesson: research sampling [online]. Arizona: Northern Arizona University [cited 24th April 2007]. 〈http://jan.ucc.nau.edu/ mezza/nur390/Mod3/sampling/lesson.html〉.

[31]. Nuwaha, F., Mulindwa, G., Kabwongyera, E. and Barenzi, J. (2000) Causes of low attendance at National Immunization Days for polio eradication in Bushenyi District, Uganda. Tropical Medicine and International Health, 5 (5), pp.364-369.

[32]. Pareek, M. and Pattison, H.M. (2000). The two-dose measles, mumps, and rubella (MMR) immunization schedule: factors affecting maternal intention to vaccinate. British Journal of General Practice, 50, pp.969-971.

[33]. Pasvol, G. (2005) Malaria. In Eddleston, M., Davidson, R., Wilkinson, R. and Pierini, S. (eds.) Oxford handbook of tropical medicine. Oxford: Oxford University Press, pp.9-37.

[34]. Polit, D.F. and Beck, C.T. (2006) Essentials of nursing research: methods, appraisal, and utilization. 6th ed., London: Lippincott Williams and Wilkins.

[35]. [P.H.A.C] Public Health Agency of Canada (2006) Poliomyelitis [online]. Ottawa: Public Health Agency of Canada [cited 21st October 2006]. http://www.phac-aspc.gc.ca/tmp-pmv/info/polio_e.html.

[36]. Silverman, D. (2005) Doing qualitative research. 2nd ed., London: SAGE Publication.

[37]. Simpson, N., Lenton, S. and Randall, R. (1995) Parental refusal to have children immunised: extent and reasons. British Medical Journal, 310 (6974), pp.225-227.

[38]. Smailbegovic, M.S., Laing, G.J. and Bedford, H. (2003). Why do parents decide against immunization? The effect of health beliefs and health professionals. Care, Health \& Development, 26 (4), pp.303-311.

[39]. Smith, S.D. (2000) Qualitative research [online]. Akron: University of Akron [cited 23rd April 2007]. <http://gozips.uakron.edu/ smiths2/quali_web_page2003.html>.

[40]. Sporton, R.K. and Francis, S. (2001) Choosing not to immunize: are parents making informed decisions? Family Practice, 18 (2), pp.181-188.

[41]. Telford, R. and Rogers, A. (2003). What influences elderly peoples' decisions about whether to accept the influenza vaccination? A qualitative study. Health Education Research, 18 (6), pp.743-753.

[42]. (UNICEF) United Nation Children Fund (2001) Combatting antivaccination rumours: lessons learned from case studies in East Africa. Nairobi: UNICEF.

[43]. Weblog, D.P. (2004) Conspiracy theories keep polio alive. New York: St. Martin's Press.

[44]. Wise, J. (2001) Pfizer accused of testing new drug without ethical approval. British Medical Journal, 322(7280), p.194.

[45]. (WHO) World Health Organization (2005a). The state of routine immunization services in Nigeria and reasons for current problems. Geneva: World Health Organization.

[46]. WHO (2005b) Polio eradication in Nigeria [online]. Geneva: World Health Organization. [Cited 18th July 2007].

http://www.who.int/countries/nga/mediacentre/backgrounders/2005/Polio_backgrounder_060505.pdf.

[47]. WHO (2006a) Poliomyelitis [online]. Geneva: World Health Organization. [cited 21st October 2006]. http:// www.who.int/mediacentre/factsheet/fs114/en.

[48]. WHO (2006b) Nigeria updates epidemiology of wild poliovirus. Abuja: World Health Organization.

[49]. WHO (2007) AFP surveillance updates. Abuja: World Health Organization.

[50]. WHO (2007a) Does polio still exist? Is it curable? [online].Geneva: World Health Organization [cited 1st January 2007] http://www.who.int/features/ga/07/en/index.html.

[51]. WHO (2007b) Expanded programme on immunization. [online]. Geneva: World Health Organization [cited 21st July 2007] http://www.who.int/countries/nga/areas/epi/en.

[52]. Yahya, M. (2006) Polio vaccines- difficult to swallow: the story of a controversy in northern Nigeria. Brighton: Institute of development Studies. 
DOI: $10.21522 /$ TIJPH.2013.05.04.Art046

ISSN: $2520-3134$

[53]. Yakasai, S.A.T. (2006) Appraisal of the 2006 provisional census figures. Kano: Triumph Publishing Company. 